\title{
Analisis Faktor yang Paling Berpengaruh Pada Keinginan Menggunakan Applikasi Grab di Kota Surabaya
}

\author{
Rinabi Tanamal \\ Teknik Informatika,Universitas Ciputra \\ UC Town, Surabaya \\ r.tanamaleciputra.ac.id
}

\begin{abstract}
In this modern communications era where many transportation applications in used by the community, competition seeking customers is the main focus by the app makers. In this study discussed the factors that most influenced by the decision to use Grab application. The respondent of this research is for Grab users in Surabaya area. This study used Intention to Use as Dependent Variable and used Independent Variables Perceived Usefulness, Perceived Ease of Use, Computer Self Efficacy and Trust. The methods which were done in this research by distributing questionnaire using non purposive sampling

and processed with SPSS program with linear regression analysis tool.
\end{abstract}

Intisari- Di era komunikasi modern ini dimana banyak sekali aplikasi transportasi yang di pergunakan oleh masyarakat, persaingan mencari pelanggan menjadi fokus utama para pembuat aplikasi. Di penelitian ini dibahas mengenai faktor yang paling mempengaruhi keputusan menggunakan aplikasi Grab. Fokus penelitian ini kepada pengguna applikasi Grab di daerah Surabaya. Penelitian ini menggunakan Intention to Use sebagai Variable Dependen dan menggunakan Variable Independen yaitu Perceived Usefulness, Perceived Ease of Use, Computer Self Eficacy dan Trust. Metode yang di lakukan pada penelitian ini dengan penyebaran kuisioner menggunakan teknik sampling non purposive sampling dan diolah dengan program SPSS dengan alat analisis regresi linier.

Kata Kunci: Regresi Linier, Grab, Jasa Transportasi, TAM

\section{Pendahuluan}

Kemajuan Teknologi komunikasi yang semakin maju membuat para pebisnis melakukan innovasi dalam menawarkan produk maupun jasa. Salah satunya adalah berkembangnya teknologi yang memanfaatkan koneksi internet sebagai media transaksi dan komunikasi. Dengan adanya Internet maka informasi lebih cepat diterima oleh pengguna. Teknologi informasi di dalam suatu bisnis yang berkembang dengan bantuan Internet disebut sebagai ECommerce. [1]

Salah satu perusahaan yang memanfaatkan $E$ Commerce ini adalah GRAB. Melalui aplikasi GRAB perusahaan dapat menghubungkan antara pengguna GRAB baik dari sisi Driver maupun dari sisi Konsumen. Dalam pemenuhan kebutuhan konsumen maka perlu diadakan explorasi ataupun survey berkelanjutan agar masalah yang ada dapat di pecahkan, peningkatan efektifitas dan efesiensi serta meningkatkan produktivitas. [2]

GRAB adalah perusahaan online jasa transportasi yang bermula dari Malaysia, yang awalnya bernama MyTeksi. Berdiri pada tahun 2012 dan mulai bertransformasi dan berkembang ke negara Asia Tenggara seperti Singapura, Indonesia, Thailand, Vietnam, dan Filipina. Sampai saat ini jumlah unduhan di Google Playstore mencapai di atas 50 juta unduhan per tanggal 27 Oktober 2017. [3]

Di dalam penelitian ini Peneliti ingin melihat respon konsumen pengguna GRAB melalui kuisioner yang di bagikan. Peneliti akan menganalisis dan memberikan masukan kepada manajemen GRAB agar bisa bersaingan dengan kompetitor sejenisnya GoCar, Grab di Indonesia spesifiknya di daerah kota Surabaya.

Karena kompetisi dan persaingan model sejenis mulai bermunculan maka penyedia jasa harus melancarkan strategi jitu agar kepuasan pelanggan dapat dipertahankan dan di tingkatkan. Peneliti ingin mencari kesimpulan berdasarkan variable Perceived Usefulness, Perceived Ease of Use, Computer Self Eficacy dan Trust yang mempengaruhi keputusan untuk menggunakan applikasi.

Variabel pertama yang digunakan adalah Perceived Ease of Use-PEOU (kemudahan penggunaan), bagaimana aplikasi Grab memberikan kemudahaan penggunaan dan pengguna tidak kesulitan menggunakan aplikasi dan tombol yang ada di Grab. Di dalam artikel Fatmawati [4] di jelaskan beberapa indikator dari PEOU sendiri adalah mudah dipelajari, mudah di operasikan, mudah di gunakan, interaksi dengan pengguna mudah, flexibel dan mahir dalam waktu singkat.

Variabel kedua adalah Perceived Usefulness-PU (Kegunaan), bagaimana aplikasi Grab ini membantu kinerja seseorang. Contoh dengan menggunakan aplikasi ini biaya transportasi dapat di tekan.

Variabel ketiga adalah Computer Self Efficacy-CSE (keahlian menggunakan komputer), bagaimana kemampuan individu dalam menggunakan sistem informasi. CSE juga menilai kemampuan individu dalam menyelesaikan tugas terkait pengapplikasian penggunaan komputer. Indikator dalam CSE adalah dapat mengakses data dari sistem, dapat mengolah data di sistem, dapat menggunakan sistem dari setiap fungsi tanpa bantuan dan menyelesaikan secara mandiri bila ada masalah di sistem. [5]

Variabel keempat adalah Trust (Kepercayaan), keyakinan bahwa individu akan menemukan apa yang diinginkan pada 
perusahaan. Variabel terakhir sebagai dependent adalah Intention to Use-ITU (Keinginan menggunakan), bagaimana aplikasi ini bisa menarik minat dari pengguna untuk menggunakan GRAB. Indikator dalam ITU diantaranya: Keinginan menggunakan Grab, Sering menggunakan Grab, Merencanakan menggunakan di masa yang akan datang. [6]

Berdasarkan latar belakang masalah diatas, peneliti berharap dapat melihat pengaruh dari Perceived Usefulness, Perceived Ease of Use, Computer Self Eficacy dan Trust terhadap keputusan menggunakan dari pelanggan pengguna GRAB. Dari penjelasan singkat mengenai kondisii persaingan jasa transportasi ini maka melalui penelitian ini, rumusan masalahnya adalah: "Faktor apa yang paling berpengaruh dalam menentukan kepuasan pelanggan Jasa GRAB dalam layanan jasa transportasi?"

Hasil akhir dari penelitian ini adalah kesimpulan dari pengambilan survey dari sampling populasi di Kota Surabaya. Hasil kesimpulan ini juga bisa di jadikan tolak ukur Manajemen Grab dalam merancang Strategi bisnisnya.

\section{LANDASAN TEORI}

\section{A. E-Commerce}

Menurut Laudon [1], e-commerce adalah internet dan web yang digunakan untuk melakukan kegiatan bisnis yang dilakukan secara otomatis dan semiotomatis dilakukan dengan menggunakan teknologi elektronik. E-commerce memungkinkan suatu perusahaan untuk berhubungan dengan sistem pemrosesan data internal dan eksternal secara lebih efisien dan fleksibel. E-commerce juga banyak dipakai untuk berhubungan dengan suplier dan mitra bisnis perusahaan, serta memenuhi permintaan dan melayani kepuasan pelanggan secara lebih baik.

E-commerce atau juga dapat didefinisikan sebagai aktivitas yang berkaitan secara langsung maupun tidak langsung dengan proses pertukaran barang dan/atau jasa dengan memanfaatkan internet sebagai medium komunikasi dan transaksi,dan salah satu aplikasi teknologi internet yang merambah dunia bisnis internal, melingkupi sistem, pendidikan pelanggan, pengembangan produk, dan pengembangan usaha. Secara luas sebagai proses bisnis yang bergantung pada sebuah sistem terotomasi.

E-commerce bertujuan untuk memungkinkan suatu perusahaan berhubungan dengan sistem pemrosesan data internal dan eksternal secara lebih efisien dan fleksibel. Salah satu jasa internet yaitu Grab yang menyediakan jasa perantara penyedia layanan kendaraan untuk pengemudi dan konsumen dan dapat diakses melalui smartphone.

\section{B. Regresi Linier}

Analisis regresi adalah suatu proses analisis yang memperhitungkan secara sistematis tentang apa yang paling mungkin terjadi dimasa yang akan datang dengan berdasarkan informasi yang sekarang dimiliki agar meminimalkan kesalahan. Pengertian analisis regresi juga dapat diartikan sebagai upaya memprediksi perubahan. Perubahan nilai suatu variabel dapat disebabkan karena adanya perubahan pada variabel-variabel lain yang mempengaruhinya. Misalnya, lama belajar terhadap hasil ujian UAS, karena adanya perubahan lama belajar maka Hasil ujian UAS juga akan berubah. Bila di hubungkan dengan kondisi bisnis/perekonomian banyak juga prediksi yang bisa saling berkaitan sehingga perubahan pada variabel lain berakibat pada perubahan variabel lainnya. Teknik yang digunakan untuk menganalisis ini adalah analisis regresi.

Analisis regresi (regression analysis) adalah suatu teknik untuk membangun persamaan dan menggunakan persamaan tersebut untuk membuat perkiraan (prediction/hipotesis). Dengan demikian, analisis regresi sering disebut sebagai analisis prediksi. Karena merupakan prediksi, maka nilai prediksi tidak selalu tetap dengan nilai riilnya, semakin kecil tingkat penyimpangan antara nilai prediksi dengan nilai riilnya, maka semakin tepat persamaan regresinya. Sehingga dapat didefinisikan bahwa: analisis regresi adalah metode statistik yang digunakan untuk menentukan kemungkinan hubungan antara variabelvariabel yang sudah di tentukan untuk di teliti.

Jadi analisis regresi secara konseptual merupakan metode sederhana untuk memeriksa hubungan antara variabel yang digambarkan dalam bentuk persamaan atau model yang menghubungkan antara variabel dependen $(Y)$ dan satu atau lebih variabel independen $(X)$. Variabel dependen dinotasikan dengan $Y$ dan himpunan dari variabel independen dinotasikan dengan $\mathrm{X} 1, \mathrm{X} 2, \mathrm{Xk}$ dimana $k$ merupakan jumlah variabel independen. Model regresi linear yang terdiri dari satu variabel dependen dan satu variabel independen disebut dengan regresi linear sederhana, sedangkan model regresi linear yang terdiri dari beberapa variabel independen dan satu variabel dependen merupakan model regresi linear berganda. Model regresi linear berganda [7]

\section{Technology Acceptance Model (TAM)}

Technology Acceptance Model (TAM) pertama kali diperkenalkan oleh Davis pada tahun 1986-1989 yang ditunukkan pada Gambar 1. TAM merupakan sebuah adaptasi dari Theory of Reasoned Action (TRA) dan mendeskripsikan bahwa tingkah laku pengguna terhadap sistem informasi/teknologi informasi itu ditentukan oleh dua keyakinan tertentu.

Sebuah sistem aplikasi tertentu akan dianggap berguna oleh calon pengguna jika mereka percaya sistem tersebut akan meningkatkan atau memfasilitasi kinerja pekerjaan mereka dalam konteks organisasi. Sistem ini dianggap memberikan kemudahan jika calon pengguna percaya bahwa sistem akan bebas dari usaha [8]

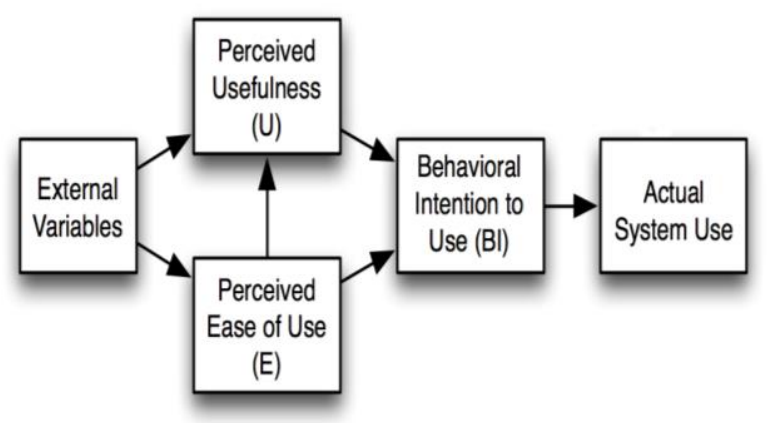

Gambar 1. Technology Acceptance Model (Davis, 1986 [9]) 


\section{Variabel Penelitian}

Variabel merupakan variasi dari objek penelitian, misalnya saja lama umur manusia divariasikan dengan diet makanan dan berat badan yang dimilikinya. Maksud dari variabel tersebut adalah terjadinya variasi antara objek yang satu dengan objek yang lainnya dalam kategori tertentu. Macam-macam Variabel dan contohnya adalah sebagai berikut:

Variabel Independen (Variabel Bebas) adalah variabel yang mempengaruhi atau sebab perubahan timbulnya variabel terikat (dependen). Variabel Independen disebut juga dengan variabel perlakuan, kausa, risiko, variabel stimulus, antecedent, variabel pengaruh, treatment, dan variabel bebas. Dapat dikatakan variabel bebas karena dapat mempengaruhi variabel lainnya. Contoh Variabel Bebas (Independen) seperti "Pengaruh konsumsi kopi terhadap pengurangan rasa mengantuk." Di sini variable Independennya adalah konsumsi kopi.

Variabel Dependen (Variabel Terikat) adalah variabel yang dipengaruhi sebagai akibat dari adanya variabel bebas. Dikatakan sebagai variabel terikat karena variabel terikat dipengaruhi oleh variabel independen (variabel bebas). Variabel Despenden disebut juga dengan variabel terikat, variabel output, konsekuen, variabel tergantung, kriteria, variabel terpengaruh. Contoh Variabel Terikat (Dependen) "Pengaruh konsumsi kopi terhadap pengurangan rasa mengantuk." Di sini variable dependennya adalah pengurangan rasa mengantuk.

Variabel Intervening adalah variabel yang tidak dapat diamati atau diukur tapi mempengaruhi variabel bebas dan variabel terikat. Variabel intervening merupakan variabel antara/penyela pada variabel bebas dan variabel terikat, sehingga variabel bebas tidak langsung mempengaruhi perubahan variabel terikat. Contoh Variabel Intervening adalah Hubungan antara Kualitas Pelayanan dengan kepuasan konsumen dan Loyalitas [10].

Variabel Kontrol adalah variabel yang dikendalikan atau dibuat konstan sehingga hubungan variabel bebas terhadap variabel terikat tidak terpengaruh oleh faktor luar yang tidak diteliti. Variabel kontrol sering digunakan sebagai pembanding melalui penelitian eksperimental. Contoh Variabel Kontrol adalah Apakah perbedaan tenaga penjual (sales force) yang lulus D3 dan SI, maka terlebih dahulu harus ditetapkan variabel kontrol contohnya berupa gaji yang sama, peralatan yang sama, lingkungan kerja yang sama. Jadi, variabel kontrol memudahkan dalam menentukan perbedaan [10]

\section{E. Computer Self Efficacy (CSE)}

Computer Self Efficacy (CSE) didefinisikan oleh Compeau dan Higgins dalam Rustiana [11] adalah sebagai judgment dari kemampuan dan keahlian seseorang dalam menggunakan komputer untuk mengerjakan tugastugasnya yang berhubungan dengan teknologi informasi.

Menurut Sanchez dan Hueros [5], ada beberapa indikator didalam CSE, diantaranya:

a. Dapat mengakses konten dari sistem

b. Dapat dengan mudah mengarahkan konten di sistem c. Dapat menyelesaikan masalah yang muncul di sistem.

d. Dapat menggunakan sistem tanpa membutuhkan bantuan mengenai kegunaan dari masing-masing fungsi

F. Perceived Ease of Use (PEOU)

Perceived Ease of Use (PEOU) digunakan untuk mengetahui tingkatan seseorang untuk percaya bahwa di dalam penggunaan sistem akan bebas dari upaya (adanya kemudahan). Kemudahan disini dapat diartikan dengan menggunakan teknologi tanpa adanya kesulitan atau tidak memerlukan usaha keras.

Menurut Davis dalam Fatmawati [4], terdapat beberapa indikator dari persepsi kemudahan penggunaan sistem informasi (perceived ease of use), yaitu: mudah dipelajari, mudah dioperasikan, mudah digunakan, interaksi dengan pengguna jelas dan mudah dipahami, fleksibel dan mudah untuk menjadi mahir.

\section{G. Perceived Usefulness (PU)}

Perceived Usefulness (PU) dimaksudkan dengan sejauh mana seseorang akan percaya bahwa dengan menggunakan sistem tertentu akan meningkatkan kinerja pekerjaannya. Hal ini dapat menggambarkan manfaat sistem dari penggunaannya yang berkaitan dengan berbagai aspek.

Menurut Davis dalam Fatmawati [4], terdapat beberapa indikator dari persepsi kebermanfaatan penggunaan sistem informasi (perceived ease of use), yaitu: meningkatkan produktivitas, memperbaiki/mempermudah pekerjaan, efisien, efektif, meningkatkan kinerja.

\section{H. Intention of Use (ITU)}

Intention on Use (ITU) merupakan perilaku niat dari pengguna untuk menggunakan suatu sistem informasi, sehingga akan menjadi kecenderungan perilaku untuk tetap menggunakan sistem informasi tersebut

Menurut Abdullah, Ward, \& Ahmed [6] ada beberapa indikator didalam Intention to Use (ITU), diantaranya:

a. Berniat menggunakan fungsi dan isi untuk membantu kegiatan akademik.

b. Berniat menggunakan fungsi dan isi sesering mungkin.

c. Berencana menggunakan fungsi dan isi di masa depan.

\section{Skala pengukuran data}

Skala Pengukuran Data adalah acuan yang digunakan sebagai tolok ukur dalam menentukan ukuran interval sehingga alat ukur bisa menghasilkan data. Menurut Widiarso [12] Skala pengukuran antara lain:

- Skala Nominal

Pengelompokan object yang di teliti menggunakan simbol seperti $1=$ Laki laki $2=$ Perempuan

- Skala Ordinal 
Pengelompokan dengan peringkat kategori seperti penentuan prestasi mahasiswa $5=$ Sangat Baik, $4=$ Baik Sekali, 3 = Baik, 2 = kurang baik, 1 = Tidak baik

- Skala Interval

Skala ini tidak memiliki nilai Nol Mutlak contohnya membagi tinggi dalam 5 interval dibawah 155, 155-159, 160$164,165-169,170-174$

\section{- Skala Ratio}

Skala ini memiliki nilai nol Mutlak contoh bila berat badan A $35 \mathrm{Kg}$ dan berat badan $\mathrm{B}=70 \mathrm{~kg}$ dapat dinyatakan bahwa rasio berat $\mathrm{A}$ dan $\mathrm{B}$ adalah $2: 1$

\section{METODE PENELITIAN}

Penelitian ini menggunakan metode SDLC dengan konsep Iterative waterfall model sesuai dengan gambar 2 sebagai berikut:

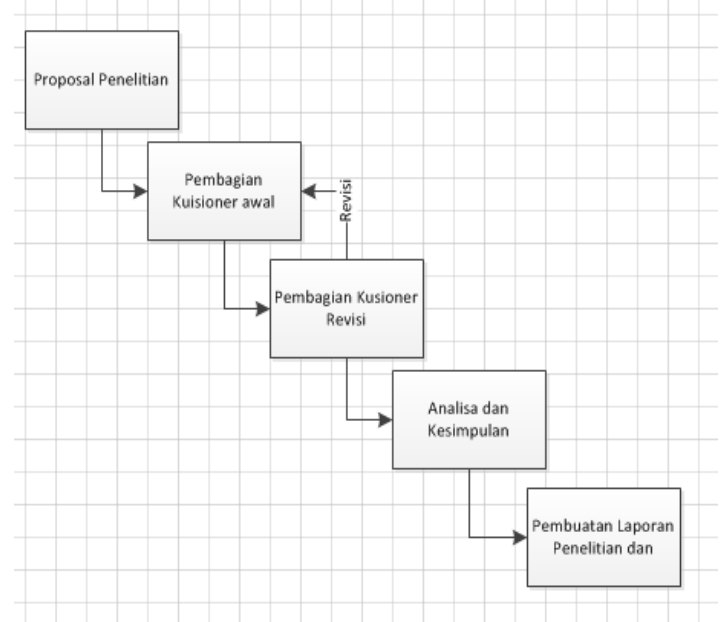

Gambar 2. Metode SDLC

Penelitian ini merupakan penelitian kuantitatif dengan mengumpulkan data yang berupa angka.

Kerangka konseptual dalam penelitian ini berupa model yang terdiri dari variable dependen dan beberapa variable independen yang merupakan rumusan dari 4 hipotesa penelitian dengan petunjuk sesuai Gambar 3:

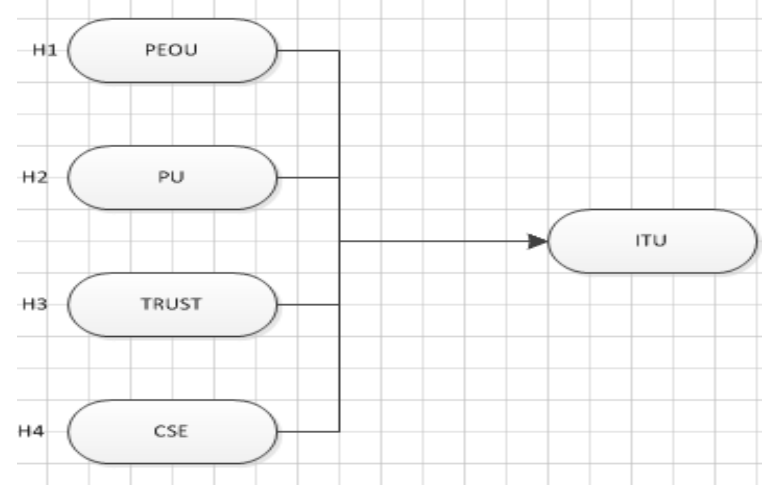

Gambar 3. Kerangka Hipotesa Penelitian

Dilihat dari hipotesa dan variabel diatas maka metode penelitian ini peneliti menggunakan alat analisis yaitu analisis regresi linier berganda. Teknik pengumpulan data yang di gunakan dalam penelitian ini adalah dengan melakukan sampling dari jumlah populasi.
Teknik sampling yang digunakan pada penelitian ini adalah teknik sampling insidental, dimana peneliti memilih sampel pada saat bertemu secara kebetulan. dan teknik purposive sampling untuk mempertimbangkan sampel yang akan dijadikan responden, dengan syarat sampel adalah pelanggan yang pernah menggunakan jasa GRAB.

Dalam artikel Sugiyono [13] ukuran sampel yang baik dalam penelitian adalah antara 30 sampai dengan 500. Jadi dalam penelitian ini sample yang dikumpulkan adalah sejumlah 78 orang.

Proses pengambilan data dilakukan dengan teknik kuesioner, dengan cara membuat survei online dan menyebar pada sosial media dengan harapan para pengguna Grab dapat mengisi di form yang di sediakan di Google. Kuisioner yang di berikan juga menggunakan skala Likert dari skor 1 Sangat tidak setuju sampai 5 sangat setuju.

Pertanyaan yang di berikan sebagai instrumen penelitian pada pengguna Grab disusun sesuai dengan Tabel 1 sebagai berikut:

TABEL 1.

PERNYATAAN UNTUK PENGGUNA GRAB

\begin{tabular}{|c|c|}
\hline Variabel & Pernyataan \\
\hline \multirow[t]{4}{*}{$\begin{array}{l}\text { Perceived } \\
\text { Usefulness } \\
(P U)\end{array}$} & \begin{tabular}{l}
\multicolumn{3}{c}{ Grab menyediakan jasa } \\
Transportasi yang \\
inginkan
\end{tabular} \\
\hline & 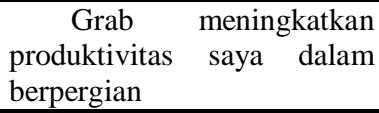 \\
\hline & $\begin{array}{l}\text { Grab dapat memenuhi } \\
\text { kebutuhan saya untuk } \\
\text { mendapatkan transportasi }\end{array}$ \\
\hline & $\begin{array}{l}\text { Grab bisa digunakan } \\
\text { untuk berpergian ketika saya } \\
\text { tidak punya kendaraan }\end{array}$ \\
\hline \multirow{4}{*}{$\begin{array}{l}\text { Perceived } \\
\text { Ease of Use } \\
(P E O U)\end{array}$} & $\begin{array}{l}\text { Mengoperasikan Grab } \\
\text { itu mudah bagi saya }\end{array}$ \\
\hline & \begin{tabular}{lr}
\multicolumn{1}{c}{ Aplikasi } & Grab \\
memudahkan & saya \\
berinteraksi dengan orang & ongang menjadi driver saya \\
\end{tabular} \\
\hline & \begin{tabular}{lr}
\multicolumn{1}{c}{ Saya dengan mudah } \\
menjadi & terampil \\
mengunakan aplikasi Grab
\end{tabular} \\
\hline & \begin{tabular}{lrr}
\multicolumn{1}{c}{ Secara } & keseluruhan \\
$\begin{array}{l}\text { aplikasi } \\
\text { digunakan }\end{array}$ & Grab & mudah \\
\end{tabular} \\
\hline \multirow[t]{4}{*}{ Trust $(T)$} & $\begin{array}{c}\text { Situs Grab dapat } \\
\text { dipercaya oleh orang banyak. }\end{array}$ \\
\hline & $\begin{array}{l}\text { Bahkan jika tidak } \\
\text { dipantau, saya percaya Grab } \\
\text { melakukan pekerjaan dengan } \\
\text { benar. }\end{array}$ \\
\hline & $\begin{array}{l}\text { Grab memberikan kesan } \\
\text { bahwa mereka menepati janji } \\
\text { dan komitmen. }\end{array}$ \\
\hline & Saya percaya GRAB. \\
\hline
\end{tabular}




\begin{tabular}{|c|c|}
\hline \multirow[t]{4}{*}{\begin{tabular}{l}
\multicolumn{2}{c}{ Computer } \\
Self $\quad$ Efficacy \\
$(C S E)$
\end{tabular}} & $\begin{array}{l}\text { Saya yakin } \\
\text { mendapatkan bantuan jika } \\
\text { mengalami kesusahan dalam } \\
\text { menggunakan Grab }\end{array}$ \\
\hline & \begin{tabular}{lll}
\multicolumn{2}{c}{ Saya } & menggunakan \\
Grab jika ada & pedoman \\
penggunaan & &
\end{tabular} \\
\hline & $\begin{array}{l}\text { Saya merasa yakin } \\
\text { dalam mencari informasi jika } \\
\text { menggunakan Grab }\end{array}$ \\
\hline & \begin{tabular}{lr}
\multicolumn{1}{c}{ Saya } & memiliki \\
keterampilan & yang \\
diperlukan & untuk \\
menggunakan Grab & \\
\end{tabular} \\
\hline \multirow[t]{4}{*}{$\begin{array}{l}\text { Behavioral } \\
\text { Intention to Use } \\
(B I T U)\end{array}$} & $\begin{array}{l}\text { Saya } \\
\text { menggunakan Grab di masa } \\
\text { depan }\end{array}$ \\
\hline & $\begin{array}{l}\text { Saya berniat untuk terus } \\
\text { menggunakan Grab di masa } \\
\text { depan }\end{array}$ \\
\hline & $\begin{array}{l}\text { Saya } \\
\text { pengalaman Grab yang saya } \\
\text { gunakan akan berlanjut di } \\
\text { masa depan }\end{array}$ \\
\hline & $\begin{array}{l}\text { Saya cenderung akan } \\
\text { merekomendasikan Grab ke } \\
\text { teman-teman saya. }\end{array}$ \\
\hline
\end{tabular}

\section{PEMBAHASAN}

Pada penelitian ini, peneliti ingin membuktikan apakah hipotesis yang ada mempunyai kontribusi positif atau negatif. Dari hipotesis yang sudah ditentukan hipotesis mana yang mempunyai pengaruh paling besar dalam mencapai keputusan pelanggan menggunakan applikasi Grab.

Dari hasil pengambilan kuisioner maka didapatkan total sebanyak 78 responden yang berhasil di survei, berikut informasi demografi responden:

\section{A. Jenis Kelamin Jenis Kelamin} 78 responses

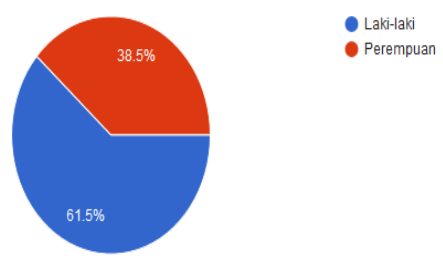

Gambar 4. Demografi Jenis Kelamin

Pada Gambar 4 didapat bahwa sebanyak 61,5\% responden adalah pria dan sebanyak $38,5 \%$ berjenis kelamin wanita.

\section{B. Penggolongan usia}

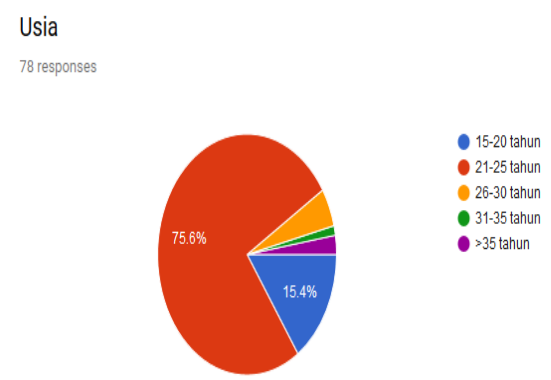

Gambar 5. Demografi Usia pengguna

Pada Gambar 5 didapat bahwa usia responden terbanyak sebesar 75,6\% adalah responden di umur 21-25 tahun diikuti responden umur 15-20 tahun sebanyak $15,4 \%$.

\section{Intensitas penggunaan Grab \\ Penggunaan aplikasi GRAB \\ 78 responses}

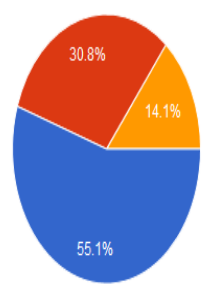

- 1-2kali per bulan

- 3-4 kali per bulan

> $>5$ per bulan

Gambar 6. Demografi Intensitas Penggunaan applikasi Grab

Pada Gambar 6 didapat intensitas penggunaan Grab sebanyak 55,1\% menggunakan aplikasi sebanyak 1-2 kali sebulan, diikuti 30,8\% menggunakan 3-4 kali per bulan dan sisanya $14,1 \%$ menggunakan aplikasi lebih dari 5 kali per bulan.

Sebelum menentukan rumusan linier berganda, maka ada pengecekan yang dilakukan peneliti yaitu: Uji validitas muka, Uji Outlier, Uji duplikat. Dalam survey kali ini tidak ada data responden terbuang. Jadi penggunaan responden sebanyak 78 bisa di proses ke tahap uji selanjutnya.

\section{Uji Validitas}

Pada uji validitas berfungsi untuk mengetahui valid dan tidaknya kuisioner yang di berikan pada setiap variable. Setiap pernyataan di setiap variable hipotesa yang diberikan kepada responden dapat menunjukkan kebenaran pengukuran

Uji validitas bertujuan untuk mengetahui sah atau valid tidaknya sebuah kuesioner.

Pada skor total yang menghasilkan nilai signifikan kurang dari 0,05 maka pernyataan valid. 


\begin{tabular}{|c|c|c|c|c|c|c|}
\hline & & T_PU & T_PEOU & T_BTU & T_T & T_CSE \\
\hline \multirow[t]{3}{*}{ PU1 } & Pearson Correlation &, $908^{-2}$ &, $778^{-1}$ &, $627^{-1}$ &, $672^{-}$ &, $701^{-1}$ \\
\hline & Sig. (2-tailed) &, 000 &, 000 &, 000 &, 000 &, 000 \\
\hline & $\mathrm{N}$ & 78 & 78 & 78 & 78 & 78 \\
\hline \multirow[t]{3}{*}{ PU2 } & Pearson Correlation & $891^{-1}$ & ,701" &, $717^{\prime \prime}$ & ,652" & $699^{\circ}$ \\
\hline & Sig. (2-tailed) & .000 &, 000 &, 000 &, 000 &, 000 \\
\hline & $\mathrm{N}$ & 78 & 78 & 78 & 78 & 78 \\
\hline \multirow[t]{3}{*}{ PU3 } & Pearson Correlation & $922^{-1}$ &, $703^{-1}$ &, $646^{\circ}$ &, $633^{-1}$ &, $729^{-1}$ \\
\hline & Sig. (2-tailed) & .000 &, 000 &, 000 &, 000 &, 000 \\
\hline & $\mathrm{N}$ & 78 & 78 & 78 & 78 & 78 \\
\hline \multirow[t]{3}{*}{ PU4 } & Pearson Correlation &, $871^{-1}$ &, $728^{-1}$ &, $540^{-4}$ &, $567^{-\prime}$ &, $686^{\circ}$ \\
\hline & Sig. (2-tailed) &, 000 &, 000 &, 000 &, 000 &, 000 \\
\hline & N & 78 & 78 & 78 & 78 & 78 \\
\hline
\end{tabular}

\begin{tabular}{|c|c|c|c|c|c|c|}
\hline & & T_PU & T_PEOU & T_BாU & $T_{-} T^{2}$ & T_CSE \\
\hline \multirow[t]{3}{*}{ PEOU1 } & Pearson Correlation &, $752^{-}$ & $860^{-\prime}$ &, $524^{\prime \prime}$ &, $662^{-}$ &, 614 \\
\hline & Sig. (2-tailed) &, 000 &, 000 &, 000 &, 000 &, 000 \\
\hline & $\mathrm{N}$ & 78 & 78 & 78 & 78 & 78 \\
\hline \multirow[t]{3}{*}{ PEOU2 } & Pearson Correlation &, $596^{-4}$ & $817^{4}$ &, $457^{\prime \prime}$ & $631^{*}$ & $600^{\circ}$ \\
\hline & Sig. (2-tailed) &, 000 &, 000 & ,000 &, 000 &, 000 \\
\hline & N & 78 & 78 & 78 & 78 & 78 \\
\hline \multirow[t]{3}{*}{ PEOU3 } & Pearson Correlation &, $730^{-4}$ & $914^{-1}$ &, $709^{-1}$ &, $752^{4}$ &, 721 \\
\hline & Sig. (2-tailed) &, 000 &, 000 &, 000 &, 000 &, 000 \\
\hline & N & 78 & 78 & 78 & 78 & 78 \\
\hline \multirow[t]{3}{*}{ PEOU4 } & Pearson Correlation &, $760^{-1}$ & $901^{*}$ &, 622 &, $643^{-}$ & 671 \\
\hline & Sig. (2-tailed) &, 000 &, 000 &, 000 &, 000 &, 000 \\
\hline & $\mathrm{N}$ & 78 & 78 & 78 & 78 & 78 \\
\hline
\end{tabular}

Gambar 8. Validitas PEOU

\begin{tabular}{|c|c|c|c|c|c|c|}
\hline & & T_PU & T_PEOU & T_BாU & T_t & T_CSE \\
\hline \multirow[t]{3}{*}{$\overline{\text { T1 }}$} & Pearson Correlation & $665^{-1}$ &, $678^{-}$ &, $779^{-4}$ & $888^{\prime \prime}$ &, $796^{4}$ \\
\hline & Sig. (2-tailed) &, 000 &, 000 & .000 & .000 &, 000 \\
\hline & $\mathrm{N}$ & 78 & 78 & 78 & 78 & 78 \\
\hline \multirow[t]{3}{*}{ T2 } & Pearson Correlation &, $711^{-}$ & $.715^{-1}$ & $710^{-4}$ & $892^{-1}$ & $813^{4}$ \\
\hline & Sig. (2-tailed) &, 000 &, 000 &, 000 &, 000 &, 000 \\
\hline & $\mathrm{N}$ & 78 & 78 & 78 & 78 & 78 \\
\hline \multirow[t]{3}{*}{ T3 } & Pearson Correlation & $.516^{-1}$ &, $651^{-1}$ & $578^{-1}$ & $829^{-1}$ &, $757^{-1}$ \\
\hline & Sig. (2-tailed) &, 000 &, 000 &, 000 &, 000 &, 000 \\
\hline & $\mathrm{N}$ & 78 & 78 & 78 & 78 & 78 \\
\hline \multirow[t]{3}{*}{$\mathrm{T} 4$} & Pearson Correlation &, $608^{-4}$ &, $693^{-1}$ &, $710^{-4}$ & $938^{-1}$ & $840^{-4}$ \\
\hline & Sig. (2-tailed) &, 000 &, 000 &, 000 &, 000 &, 000 \\
\hline & $\mathrm{N}$ & 78 & 78 & 78 & 78 & 78 \\
\hline
\end{tabular}

Gambar 9. Validitas Trust

\begin{tabular}{|c|c|c|c|c|c|c|}
\hline & & T_PU & T_PEOU & T_BாU & $T_{-} T$ & T_CSE \\
\hline \multirow[t]{3}{*}{ CSE1 } & Pearson Correlation &, $645^{\prime \prime}$ &, $613^{-2}$ &, $660^{-1}$ & $830^{-1}$ & $891^{+}$ \\
\hline & Sig. (2-tailed) &, 000 & .000 & .000 & .000 & .000 \\
\hline & $\mathrm{N}$ & 78 & 78 & 78 & 78 & 78 \\
\hline \multirow[t]{3}{*}{ CSE2 } & Pearson Correlation &, $662^{-1}$ & ,639-1 & $677^{\circ}$ & $.826^{-1}$ & $917^{\prime}$ \\
\hline & Sig. (2-tailed) &, 000 &, 000 &, 000 &, 000 &, 000 \\
\hline & $\mathrm{N}$ & 78 & 78 & 78 & 78 & 78 \\
\hline \multirow[t]{3}{*}{ CSE3 } & Pearson Correlation &, $695^{-1}$ & $656^{-1}$ &, $644^{-4}$ &, $743^{-1}$ & $890^{-1}$ \\
\hline & Sig. (2-tailed) &, 000 &, 000 &, 000 &, 000 & .000 \\
\hline & $\mathrm{N}$ & 78 & 78 & 78 & 78 & 78 \\
\hline \multirow[t]{3}{*}{ CSE 4} & Pearson Correlation &, $781^{-\prime}$ &, $749^{-1}$ &, $694^{-4}$ &, $808^{-4}$ &, $858^{\circ}$ \\
\hline & Sig. (2-tailed) &, 000 &, 000 &, 000 &, 000 & .000 \\
\hline & $\mathrm{N}$ & 78 & 78 & 78 & 78 & 78 \\
\hline
\end{tabular}

Gambar 10. Validitas CSE

\begin{tabular}{|c|c|c|c|c|c|c|}
\hline & & T_PU & T_PEOU & T_BாU & T_T & T_CSE \\
\hline \multirow[t]{3}{*}{ BாU1 } & Pearson Correlation &, $649^{-}$ &, $612^{-4}$ &, $915^{-1}$ &, $685^{4}$ & $649^{-4}$ \\
\hline & Sig. (2-tailed) &, 000 &, 000 &, 000 &, 000 &, 000 \\
\hline & $\mathrm{N}$ & 78 & 78 & 78 & 78 & 78 \\
\hline \multirow[t]{3}{*}{ BாU2 } & Pearson Correlation & ,589- &, $554^{\prime \prime}$ & $952^{-}$ & $688^{-4}$ & $657^{-1}$ \\
\hline & Sig. (2-tailed) &, 000 &, 000 &, 000 &, 000 &, 000 \\
\hline & $\mathrm{N}$ & 78 & 78 & 78 & 78 & 78 \\
\hline \multirow[t]{3}{*}{ BாU3 } & Pearson Correlation & $680^{-}$ &, $643^{-}$ & $929^{\circ}$ &, $788^{-}$ &, $771^{-1}$ \\
\hline & Sig. (2-tailed) &, 000 &, 000 &, 000 & , 000 &, 000 \\
\hline & $\mathrm{N}$ & 78 & 78 & 78 & 78 & 78 \\
\hline \multirow[t]{3}{*}{ BாU4 } & Pearson Correlation &, $714^{-4}$ &, $665^{*}$ &, 920 &, $757^{-}$ &, $733^{-4}$ \\
\hline & Sig. (2-tailed) &, 000 & , 000 &, 000 &, 000 &, 000 \\
\hline & $\mathrm{N}$ & 78 & 78 & 78 & 78 & 78 \\
\hline
\end{tabular}

Pada Gambar 7-11 menunjukkan bahwa nilai significant pada setiap pernyataan pada variable hipotesa PU, PEOU, Trust, CSE, ITU menunjukkan bahwa nilai kurang dari 0,05 menunjukkan bawah semua pernyataan adalah valid.

\section{Uji Reabilitas}

Uji realibilitas digunakan untuk mengetahui sejauh mana hasil pengukuran tetap konsisten, dan bila dilakukan pengukuran lebih dari dua kali terhadap gejala yang sama dengan menggunakan alat pengukur yang sama hasilnya tetap konsisten. Di penelitian ini digunakan standard nilai Cronbach Alpha yang lebih besar dari 0,7. [14]

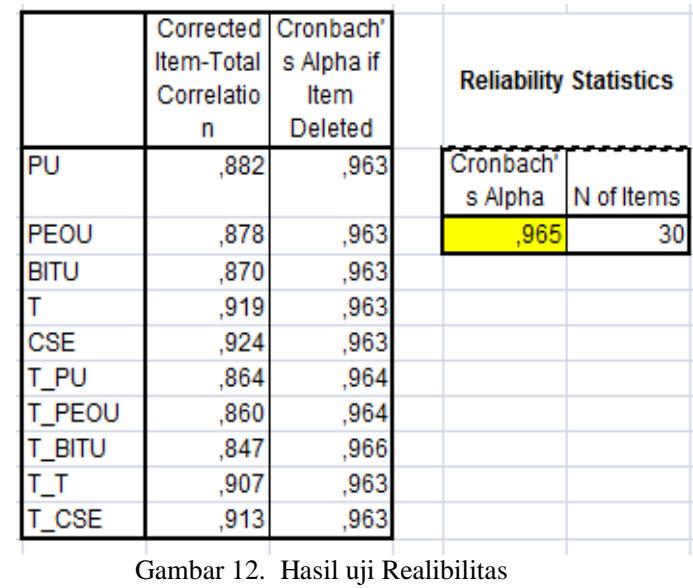

Pada gambar 12 dapat dijelaskan bahwa variable hipotesa pada setiap pernyataan yang diberikan semuanya memiliki nilai Cronbach Alpha lebih dari 0,7. Nilai rata-rata dari PU adalah 0,963. Nilai rata-rata dari PEOU adalah 0,963. Nilai rata-rata dari Trust adalah 0,963. Nilai rata dari CSE adalah 0,963dan Nilai rata-rata dari BITU adalah 0,963.

\section{Uji Normalitas}

Uji Normalitas bertujuan untuk menguji apakah model regresi normal. Model regresi normal dengan penyebaran data statistik pada sumbu diagonal dari grafik distribusi normal. Pengujian dilakukan dengan menggunakan metode uji Kolmogorov Smirnov Dengan nilai signifikansi > 0,05, maka model telah terdistribusi normal. 


\begin{tabular}{|c|c|c|}
\hline \multicolumn{3}{|c|}{ One-Sample Kolmogorov-Smirnov Test } \\
\hline & & $\begin{array}{c}\text { Unstandardized } \\
\text { Residual }\end{array}$ \\
\hline \multicolumn{2}{|l|}{$\mathrm{N}$} & 78 \\
\hline \multirow{2}{*}{$\begin{array}{l}\text { Normal } \\
\text { Parametersa,b }\end{array}$} & Mean &, 0000000 \\
\hline & Std. Deviation & 2,24975548 \\
\hline \multirow{3}{*}{$\begin{array}{l}\text { Most Extreme } \\
\text { Differences }\end{array}$} & Absolute & , 134 \\
\hline & Positive & 134 \\
\hline & Negative &,- 077 \\
\hline \multicolumn{2}{|c|}{ Kolmogorov-Smirnov Z } & 1,185 \\
\hline \multicolumn{2}{|c|}{ Asymp. Sig. (2-tailed) } &, 120 \\
\hline
\end{tabular}

Gambar 13. Hasil Uji Normalitas

Dari Gambar 13 dapat dibuktikan bahwa distribusi data normal.

\section{Uji Multikolinieritas}

Pada Uji selanjutnya yaitu Uji Multikolinieritas yang berfungsi untuk melihat adanya multikolinieritas di dalam model regresi. Standard yang digunakan adalah nilai VIF lebih kecil dari 10 dan mempunyai nilai tolerence lebih besar dari 0,1 . Hasil yang baik adalah tidak adanya multikolinieritas dalam model regresi.

\begin{tabular}{|c|c|c|c|c|c|c|c|}
\hline \multicolumn{8}{|c|}{ Coefficientsa } \\
\hline \multirow[b]{2}{*}{ Model } & \multicolumn{2}{|c|}{$\begin{array}{c}\text { Unstandardized } \\
\text { Coefficients }\end{array}$} & \multirow{2}{*}{\begin{tabular}{|c|}
$\begin{array}{c}\text { Standardized } \\
\text { Coefficients }\end{array}$ \\
Beta \\
\end{tabular}} & \multirow[b]{2}{*}{$t$} & \multirow[b]{2}{*}{ Sig. } & \multicolumn{2}{|c|}{$\begin{array}{c}\text { Collinearity } \\
\text { Statistics }\end{array}$} \\
\hline & $B$ & Std. Error & & & & Tolerance & VIF \\
\hline 1 (Constant & $-1,323$ & 1,425 & & -928 & 356 & & \\
\hline T_PU & , 417 & 157 &, 356 & 2,651 &, 010 &, 256 & 3,912 \\
\hline T_PEOU &,- 099 &, 155 & ;085 & -636 &, 527 & 259 & 3,867 \\
\hline T_T &, 724 & 208 &, 607 & 3,484 &, 001 & ,152 & 6,565 \\
\hline T_CSE & -013 & 218 & $; 011$ &,- 058 &, 954 & , 138 & 7,272 \\
\hline
\end{tabular}

Di Gambar 14 dapat dilihat nilai tolerance untuk variabel PU adalah 0,256, variable PEOU adalah 0,259, untuk variable Trust adalah 0,152 dan variable CSE adalah 0,138. Di mana nilai tolerance semua variable di atas 0,1 .

Dari hasil VIF juga dapat dibuktikan nilai masingmasing variable independen adalah: variable PU dengan nilai 3,912, variable PEOU dengan nilai 3,867, variable Trust dengan nilai 6,565 dan Variable CSE dengan nilai 7,272. Dari 4 variable, semua nilai dibawah standard nilai 10. Maka hasil dari uji multikolinieritas membuktikan bahwa tidak terjadi multikolinieritas di penelitian ini.

\section{Uji Heteroskedastisitas}

Pengujian ini juga dinamakan uji asumsi klasik. Pengujian ini dapat dilakukan dengan menggunakan uji Glejser di mana bila nilai signifikansi lebih besar 0,05, maka tidak terjadi heteroskedastisitas dan bila lebih kecil dari 0,05 maka mengalami tidak mengalami heterokesdastisitas.

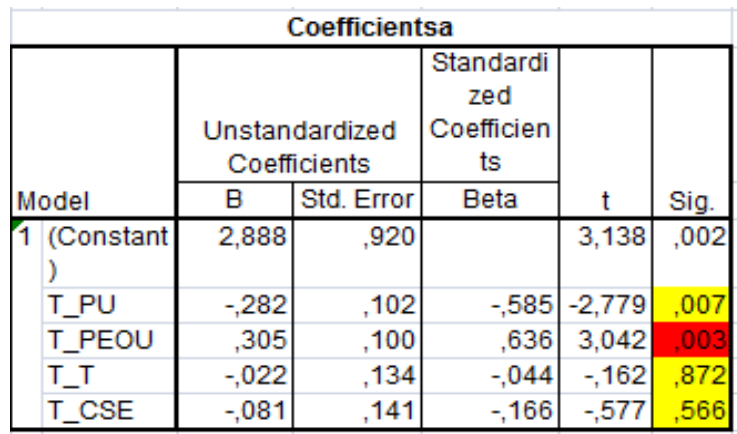

Gambar 15. Hasil Uji Heteroskedastisitas

Pada Gambar 15 dapat dilihat bahwa nilai signifikansi yang dimiliki tiap variabel bebas adalah heteroskedastisitas, nilai significant di atas 0,05 . Kecuali variable PEOU karena nilai signifikansi kurang dari 0,05 maka variable PEOU dikatakan Homoskedastisitas.

\section{Uji Autokorelasi}

Tujuan dari uji autokorelasi adalah untuk mengetahui apakah. Suatu model regresi yang baik adalah model regresi yang tidak terjadi autokorelasi. Pengujian autokorelasi dapat dilakukan dengan uji Durbin-Watson, dengan syarat $\mathrm{dU}<\mathrm{dW}<4-\mathrm{dU}$ maka nilai Durbin Watson dikatakan tidak terjadi autokorelasi.

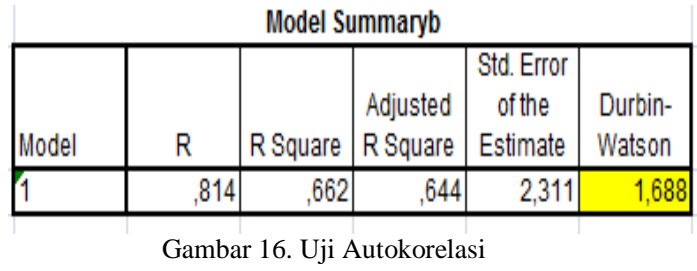

Di Gambar 16 diketahui bahwa nilai Durbin Watson adalah 1,688. Langkah selanjutnya adalah mencari tabel statistik Durbin watson dengan repsonden sebanyak 78 . Diketahui bahwa dU adalah 1,658 dan menggunakan rumusan $\mathrm{dU}<\mathrm{dW}<4-\mathrm{dU}$ maka hasilnya adalah: 1,658 $<1,688<2,35$.

Dengan demikian dapat dinyatakan bahwa tidak terjadi autokorelasi, karena nilai $\mathrm{dW}$ berada diantara nilai $\mathrm{dU}$ dan nilai 4-dU.

\section{Uji Linieritas}

Tujuan dari uji linieritas adalah untuk menguji apakah terdapat hubungan yang bersifat linier secara signifikan antar Variabel PU, PEOU, Trust, CSE dan variabel ITU, data yang baik seharusnya terjadi hubungan linier antara variabel independen (x) dan Independen (y). Bila nilai signifikansi linierity lebih kecil dari 0,05, maka terjadi hubungan linier antara $\mathrm{x}$ dan $\mathrm{y}$. 


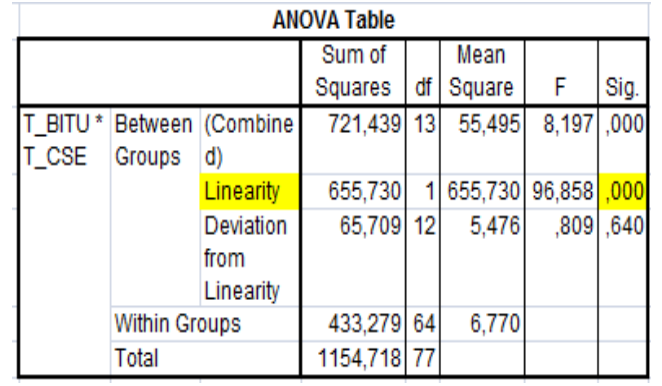

Gambar 17. Uji Linieritas

Dari Gambar 17 di atas dapat dilihat bahwa nilai sig linierity menunjukan bahwa Total variabel memiliki nilai signifikansi $<0,05$, dengan demikian variabel PEOU, PU, CSE, Trust, dan ITU mempunyai hubungan linier secara signifikan.

\section{Uji Regresi Linier}

Pada uji regresi linier digunakan untuk mengetahui hubungan variabel PU, PEOU, CSE, Trust terhadap BITU yang dinyatakan dalam persamaan :

$$
\mathrm{Y}=\mathrm{a}+\mathrm{b} 1 \mathrm{x} 1+\mathrm{b} 2 \times 2+\mathrm{b} 3 \times 3+\mathrm{e}
$$

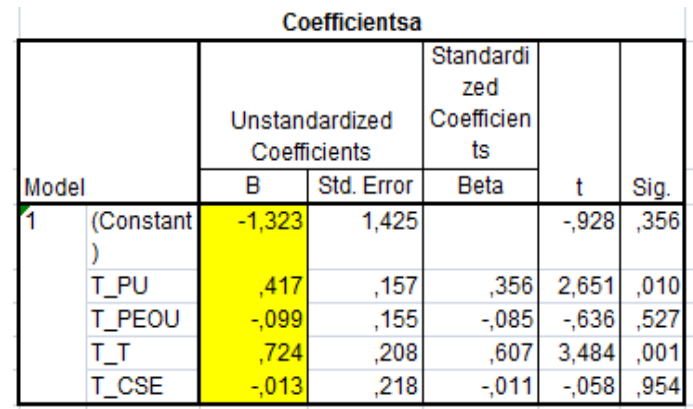

Gambar 18. Uji Analisis Regresi Linier

Dari hasil gambar 18 maka hasil dari rumusan Regresi Linier adalah:

$$
Y=-1,323+0,417 X 1-0,99 X 2+0,724 X 3-0,13 X 4
$$

Koefesien regresi untuk variabel $\mathrm{X}_{1}(\mathrm{PU})$ bernilai positif, artinya adanya hubungan yang searah antara variabel PU terhadap variabel ITU. Koefesien regresi variabel $\mathrm{X}_{1}$ menunjukan nilai sebesar 0,417 .

Koefesien regresi untuk variabel $\mathrm{X}_{2}$ (PEOU) bernilai negatif, menunjukan adanya hubungan yang tidak searah antara variabel PEOU terhadap variabel ITU. Koefesien regresi variabel $\mathrm{X}_{2}$ menunjukan nilai sebesar -0,099.

Koefesien regresi untuk variabel $\mathrm{X}_{3}$ (Trust) bernilai positif, menunjukan adanya hubungan yang searah antara variabel Trust terhadap variabel ITU. Koefesien regresi variabel $\mathrm{X}_{3}$ menunjukan nilai sebesar 0,724 Koefesien regresi untuk variabel $\mathrm{X}_{4}$ (CSE) bernilai negatif, menunjukan adanya hubungan yang tidak searah antara variabel CSE terhadap variabel ITU. Koefesien regresi variabel $\mathrm{X}_{4}$ menunjukan nilai sebesar $-0,013$.
Uji T dimanfaatkan untuk mengetahui pengaruh dari setiap variabel independen PU, PEOU, CSE, Trust terhadap variabel dependen Intention to Use. Apabila hasil uji T dengan nilai signifikan $<0.05$ dan nilai $\mathrm{T}$ hitung $>\mathrm{T}$ tabel maka artinya variabel bebas secara individual atau parsial memiliki pengaruh signifikan terhadap variabel terkait.

T Tabel yang digunakan adalah jumlah responden - 4 variabel $=74$ dan bisa di dapatkan bahwa t tabel dengan signifikan 5\% adalah 1,666.

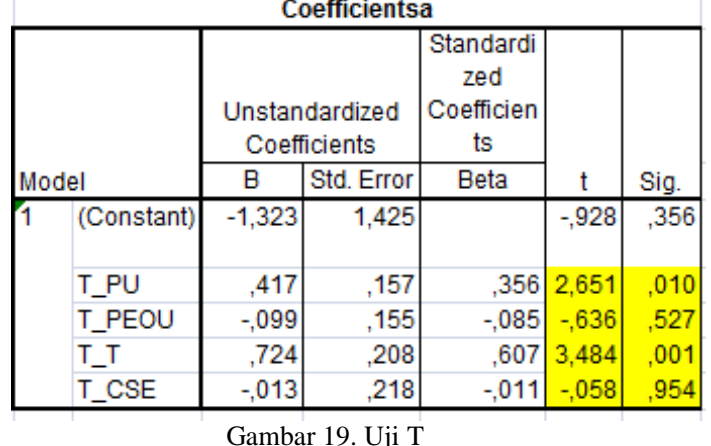

Pada Gambar 19 dijelaskan Uji T sebagai berikut:

\section{- Variabel PU}

Pada variabel PU mendapatkan nilai thitung sebesar 2,651 dengan nilai sig sebesar 0,010 dan nilai $\mathrm{t}_{\text {tabel }}$ sebesar 1,666. Dari hasil uji ini dapat dikatakan bahwa variabel PU memiliki pengaruh signifikan terhadap Intention to Use. Maka hipotesis 1 diterima.

\section{- Variabel PEOU}

Pada variabel PEOU mendapatkan nilai $t_{\text {hitung sebesar - }}$ 0,636 dengan nilai sig sebesar 0,527 dan nilai tabel sebesar 1,666. Maka dari hasil uji ini dapat dikatakan bahwa variabel PEOU tidak memiliki pengaruh signifikan terhadap Intention to Use namun pengaruh negatif. Maka hipotesis 2 ditolak.

\section{- Variabel Trust}

Pada variabel Trust mendapatkan nilai thitung sebesar 3,484 dengan nilai sig sebesar 0,001 dan nilai tabel sebesar 1,666. Dari hasil uji ini maka dapat dikatakan bahwa variabel Trust memiliki pengaruh signifikan terhadap Intention to Use. Maka hipotesis 3 diterima.

\section{- Variabel CSE}

Pada variabel CSE mendapatkan nilai thitung sebesar 0,058 dengan nilai sig sebesar 0,954 dan nilai tabel sebesar 1,666. Dari hasil uji ini dapat dikatakan bahwa variabel CSE tidak memiliki pengaruh signifikan terhadap Intention to Use dan mempunyai pengaruh negatif. Maka hipotesis 4 ditolak.

\section{Uji Signifikansi Simultan (Uji F)}

Uji $F$ bertujuan untuk mengetahui pengaruh variabel independen pada penelitian ini terhadap intention to use yang menjadi variabel dependen secara simultan atau bersamaan.

\section{Uji Signifikansi Parsial (Uji T)}




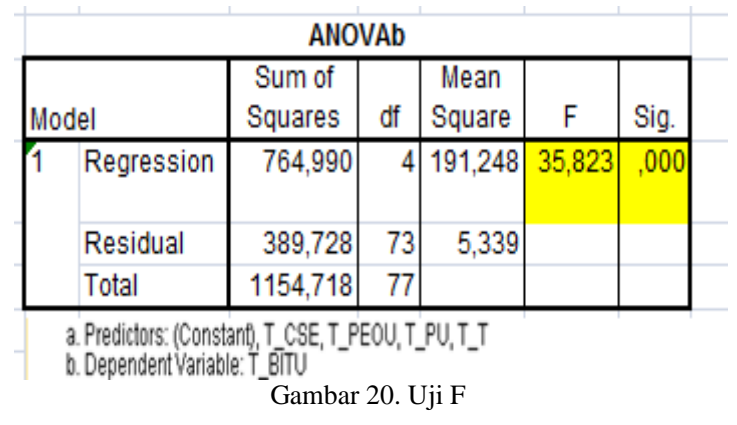

Pada Gambar 20 hasil dari uji F didapatkan bahwa nilai $F_{\text {hitung }}$ sebesar 35,823 dengan nilai signifikansi sebesar 0,000 , yang berarti lebih besar dari nilai $\mathrm{F}_{\text {tabel }}$ sebesar 2,50 dan nilai signifikansi 0,000 yang berarti lebih kecil dari 0,05 .

Membuktikan bahwa variabel PU, PEOU, Trust dan CSE secara simultan atau bersamaan memiliki pengaruh yang positif dan signifikan terhadap niat menggunakan aplikasi Grab di Surabaya.

\section{Uji Koefisien Determinasi (Uji $\mathbf{R}^{2}$ )}

Pada uji yang terakhir yaitu uji Koefisien determinasi $\left(R^{2}\right)$ yang bertujuan untuk mengukur seberapa jauh kemampuan sebuah model menerangkan variasi variabel dependen. Nilai koefisien determinasi adalah antara nol dan satu.

Nilai $\mathrm{R}^{2}$ yang kecil berarti kemampuan variabelvariabel independen dalam menjelaskan variabel dependen sangat terbatas atau tidak mempengaruhi, apabila $\mathrm{R}^{2}$ mendekati 1 maka variabel independen mempengaruhi atau memberikan hampir semua informasi yang dibutuhkan.

\begin{tabular}{|l|r|r|r|r|}
\hline \multicolumn{1}{|c|}{ Model Summaryb } \\
\hline Model & R & R Square & $\begin{array}{r}\text { Adjusted } \\
\text { R Square }\end{array}$ & $\begin{array}{c}\text { Std. Error } \\
\text { of the } \\
\text { Estimate }\end{array}$ \\
\hline 1 &, 814 &, 662 &, 644 & 2,311 \\
\hline $\begin{array}{l}\text { a. Predictors: (Constant), T_CSE, T_PEOU, T_PU, T_T } \\
\text { b. Dependent Variable: T_BiTU }\end{array}$ \\
Gambar 21. Hasil Uj Koefisien Determinasi (Uji R ${ }^{2}$ )
\end{tabular}

Setelah dilakukan uji koefisien determinasi ( Uji $\mathrm{R}^{2}$ ) seperti yang ditampilkan pada Gambar 21 maka bisa dilihat bahwa nilai adjusted $R$ square sebesar 0,644, artinya terdapat $64,4 \%$ kemungkinan keinginan untuk menggunakan aplikasi Grab yang di pengaruhi dari variable Perceived Usefulness (PU), Perceived Ease of Use (PEOU), Computer Self Efficacy (CSE), dan Trust(T). Dan sisanya sebesar $35,6 \%$ dipengaruhi oleh variabel diluar penelitian ini.

\section{KESIMPULAN}

Hasil penelitian pada variabel PU memiliki pengaruh positif dan signifikan terhadap niat menggunakan aplikasi Grab artinya bila semakin baik kegunaan Aplikasi Grab dalam meningkatkan kinerja pengguna, maka semakin tinggi tingkat niat pengguna dalam menggunakan aplikasi Grab.
Pada penelitian variabel PEOU memiliki pengaruh negatif dan tidak signifikan terhadap niat pengguna dalam menggunakan aplikasi Grab. Dikarenakan nilai menunjukkan hasil negatif dan tidak signifikan terhadap niat menggunakan aplikasi Grab artinya bahwa aplikasi dirasakan sulit untuk dimengerti.

Hasil penelitian pada variabel Trust memiliki nilai tertinggi, berpengaruh positif dan signifikan terhadap niat menggunakan aplikasi Grab artinya bila semakin tinggi tingkat kepercayaan dalam Aplikasi Grab, maka semakin tinggi juga tingkat niat pengguna dalam menggunakan aplikasi Grab.

Pada variabel terakhir CSE, berpengaruh negatif pada pengguna aplikasi Grab dan tidak signifikan terhadap niat menggunakan aplikasi Grab. Jadi pengguna yang sudah terbiasa dengan menggunakan smartphone atau gadget maka tidak berpengaruh terhadap penggunaan aplikasi Grab namun pengoperasian yang kurang bersahabat juga menurunkan nilai PEOU.

Hasil penelitian dari seluruh variabel independen yaitu Perceived Usefulness (PU), Perceived Ease of Use (PEOU), Computer Self Efficacy (CSE), dan Trust(T) secara bersamasama membuktikan bahwa seluruh variabel independen berpengaruh secara simultan terhadap niat pengguna dalam menggunakan aplikasi Grab.

Dalam persamaan regresi linier:

$\mathrm{Y}=-1,323+0,417 \mathrm{X} 1-0,99 \mathrm{X} 2+0,724 \mathrm{X} 3-0,13 \mathrm{X} 4$

Variabel Trust memiliki pengaruh paling signifikan terhadap niat pengguna dalam menggunakan aplikasi Grab, maka di harapkan bahwa pengembangan di variable ini akan berdampak sangat besar dalam peningkatan niat pengguna untuk penggunaan aplikasi Grab.

Maka dengan demikian peneliti sudah menjawab rumusan masalah "Faktor apa yang paling berpengaruh dalam menentukan kepuasan pelanggan Jasa GRAB dalam layanan jasa transportasi?" yaitu Faktor Trust yang paling berpengaruh dalam meraih niat pengguna aplikasi Grab.

\section{DAFTAR PUSTAKA}

[1] K. C. Laudon dan J. P. Laudon, "Management Information Systems: Managing the Digital Firm," Journal Information Systems, 2012.

[2] J. Jauhari, "Upaya Pengembangan Usaha Kecil dan Menengah (UKM) dengan Memanfaatkan ECommerce,” Jurnal Sistem Informasi., 2010.

[3] “Google Playstore," Grab Taxi, [Online]. Available: https://play.google.com/store/apps/details?id=com.gr abtaxi.passenger. [Diakses 27 October 2017].

[4] E. Fatmawati, "Technology Acceptance Model (TAM) Untuk Menganalisis Penerimaan Terhadap Sistem Informasi Perpustakaan," Jurnal Iqra', vol. 09, no. 01, 2015.

[5] R. A. Sanchez dan A. D. Hueros, "Motivational Factors That Influence The Acceptance of Moodle 
Using TAM," Computers in Human Behavior, pp. 1632-1640, 2010.

[6] F. abdullah, R. Ward dan E. Ahmed, "Investigating the influence of the most commonly used external variabels of TAM on students' PEOU and PU of eportofolio," 2016.

[7] J. J. Faraway, Extending the Linear Model with R: Generalized Linear, Mixed Effects and Nonparametric Regression Models, London: CRC Press, 2016.

[8] D. C. Yen, C. S. Wu, F. F. Cheng dan Y. W. Huang, 'Determinants of users' intention to adopt wireless technology: An empirical study by integrating TTF with TAM," Computers in Human Behavior (ScienceDirect), no. 26, pp. 906-915, March 2010.

[9] F. D. Davis, "Perceived Usefulness, Perceived Ease of Use, and User Acceptance of Information Technology," MIS Quarterly, vol. 3, no. 13, pp. 319340, 1989.

[10] M. Sari, "Pengaruh Manahemen Laba Terhadap Pengungkapan Corporate social Responsibility: Variabel Anteseden dan Variabel Moderasi," Akuntabilitas, 2016.

[11] Rustiana, "Computer Self Efficacy (CSE) Mahasiswa Akuntansi dalam Penggunaan Teknologi Informasi: Tinjauan Perspektif Gender," Jurnal Akuntansi \& Keuangan, pp. 29-39, 2004.

[12] Widhiarso, "Penerapan Model MIMIC untuk Menguji Konsistensi Hasil Pengukuran melalui Skala," Journal of Education and Learning (EduLearn), 2012.

[13] Sugiyono., Metode Penelitian Pendidikan, Bandung: CV Alfabeta, 2014.

[14] I. Ghozali, Aplikasi Analisis Multivariate Dengan Program SPSS., Semarang, Indonesia: BP Universitas Diponegoro, 2011..

[15] M. Sari, Pengaruh Manajemen Laba Terhadap Pengungkapan Corporate social Responsibility, Akuntanbilitas, 2016. 